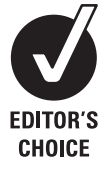

${ }^{1}$ WHO Collaborating Centre for Capacity Building in HIV

Surveillance, Andrija Stampar School of Public Health, School of Medicine, Rockefellerova 4, 10000 Zagreb, Croatia;

${ }^{2}$ Communicable Diseases Unit, World Health Organization Regional Office for Europe Scherfigsvej 8, DK-2100

Copenhagen $\emptyset$, Denmark

Correspondence to:

Dr Ivana Bozicevic, WHO Collaborating Centre for Capacity Building in HIV Surveillance, Andrija Stampar School of Public Health, School of Medicine,

Rockefellerova 4, 10000

Zagreb, Croatia; Ivana.

Bozicevic23@gmail.com

Accepted 20 March 2009

\title{
HIV epidemics among men who have sex with men in central and eastern Europe
}

\author{
I Bozicevic, ${ }^{1}$ L Voncina, ${ }^{1}$ L Zigrovic, ${ }^{1}$ M Munz, ${ }^{2}$ J V Lazarus ${ }^{2}$
}

Male-to-male sex is the major route of HIV transmission in high-income countries, and the emerging data from low-income and middleincome countries indicate that men who have sex with men (MSM) bear a substantial burden of HIV epidemics there as well. ${ }^{12}$

It is estimated that 1.5 (range 1.1-1.9) million people were living with HIV in the countries of central and eastern Europe (CCEE) in 2007, with an estimated adult prevalence (15-49 years old) of $0.8 \%$ (range $0.6 \%-1.1 \%$ ). ${ }^{3}$ Injecting drug use remains the main mode of HIV transmission in the 15 countries of the former Soviet Union, though there has been an increase in the number of reported heterosexually acquired infections. ${ }^{4}$ In the other countries of eastern Europe, the main modes of transmission are sexual: both heterosexual and through male-to-male sex. ${ }^{5}$ MSM remain the group at the greatest risk of HIV in western Europe, because of high levels of HIVrelated risk behaviours and increasing incidence of sexually transmitted infections (STIs). ${ }^{67}$

In the CCEE, data on the epidemiology of HIV among MSM are less available compared with other vulnerable groups, which has partly been attributed to specific social conditions and stigmatisation of homosexuality in post-communist, transitional societies. ${ }^{89}$ In the recently published assessment of the quality of HIV sero-surveillance in low-income and middle-income countries, only one country of eastern Europe and central Asia (Ukraine) was assessed as having a fully functioning surveillance system. ${ }^{10}$ The key weaknesses identified were the over-reliance on HIV and AIDS case reporting in longer-term tracking of the epidemic and few studies conducted among atrisk groups other than injecting drug users. The concerns about insufficient quality of data on population health and their limited usefulness for informed policy decisions, coupled with weak infrastructure for communicable disease control, have been well recognised by experts. ${ }^{11}$

To address the apparent gap in knowledge about the level of HIV and risk behaviours among MSM in eastern Europe, in 2008 the World Health Organization Regional Office for Europe (WHO/ Europe) commissioned a study that aimed to review the available data on HIV and STIs among MSM in the CCEE, the response to the epidemic and the evidence on stigma and discrimination against MSM. This paper aims to present the results of this study.

\section{METHODS}

We used the classification of the European Centre for the Epidemiological Monitoring of HIV/AIDS
(EuroHIV), which groups the CCEE into a central region (Albania, Bosnia and Herzegovina, Bulgaria, Croatia, Cyprus, Czech Republic, Hungary, the former Yugoslav Republic of Macedonia, Poland, Romania, Serbia and Montenegro, Slovakia, Slovenia, Turkey), and an eastern region (Armenia, Azerbaijan, Belarus, Estonia, Georgia, Kazakhstan, Kyrgyzstan, Latvia, Lithuania, Republic of Moldova, Russian Federation, Tajikistan, Turkmenistan, Ukraine, Uzbekistan).

\section{Data collection}

In each country, researchers proposed by WHO/ Europe were asked to collect the literature on HIV epidemiology among MSM, prevention responses and stigma and discrimination in the local language and/or in English, published between 1 January 2000 and 1 February 2008. Where data were not available after 2000, we asked country collaborators to send us the latest available data. The literature included published papers and reports on HIV, STIs and behavioural surveillance surveys, research studies carried out among MSM, published abstracts, conference reports and "grey" literature available in the country. In order to receive comparable reports, all collaborators were sent a template of a country report and a list of 17 biological and behavioural indicators with specific time frames. If these data were not available, collaborators in the countries were asked to provide existing data and state the time frame for each indicator.

Additional literature searches were conducted at the WHO Collaborating Centre for Capacity Building in HIV Surveillance in Zagreb using Pubmed and Embase. The following medical subject heading (MeSH) terms were used for PubMed, while the same terms were used as keywords in Embase: "Homosexual, Men" OR "Homosexual" which were cross-referenced with the keyword (AND) "HIV" OR the MeSH term "Human Immunodeficiency Virus" and the keywords "Eastern Europe", "prevention" and "stigmatization" and limited to reports in the English language, published since 1 January 2000.

The EuroHIV report was used to assess the HIV cases reported among MSM in the CCEE. 5 Data on coverage with HIV prevention interventions were collected from the most recent proposals for the Global Fund to Fight AIDS, Tuberculosis and Malaria (GFATM) grants as this was considered the source that could provide the most comparable data and because it was not possible to find good quality data on the prevention responses. 
Table 1 HIV infections newly diagnosed in 2006 according to the key HIV transmission groups*, as a percentage of the total number of HIV cases reported in 2006

\begin{tabular}{|c|c|c|c|c|}
\hline Country & $\begin{array}{l}\text { Men who have sex } \\
\text { with men }(\%)\end{array}$ & $\begin{array}{l}\text { Injecting drug users } \\
(\%)\end{array}$ & $\begin{array}{l}\text { People infected by } \\
\text { heterosexual contact } \\
\text { (\%) }\end{array}$ & $\begin{array}{l}\text { Total number of HIV } \\
\text { cases reported }\end{array}$ \\
\hline Albania & 0 & 0 & 84.4 & 32 \\
\hline Armenia & 3.0 & 36.4 & 56.1 & 66 \\
\hline Belarus & 0.1 & 33.0 & 63.3 & 733 \\
\hline Bosnia and Herzegovina & 29.4 & 17.6 & 47.1 & 17 \\
\hline Bulgaria & 11.0 & 37.4 & 50.5 & 91 \\
\hline Croatia & 53.0 & 6.1 & 33.3 & 66 \\
\hline Cyprus & 23.5 & 0 & 76.5 & 34 \\
\hline Czech Republic & 55.9 & 5.4 & 29.0 & 93 \\
\hline Georgia & 1.4 & 56.5 & 39.5 & 276 \\
\hline Hungary & 45.7 & 0 & 17.3 & 81 \\
\hline Kazakhstan & 0.5 & 66.6 & 18.6 & 1745 \\
\hline Kyrgyzstan & 0.4 & 68.9 & 29.1 & 244 \\
\hline Latvia & 5.0 & 36.1 & 29.1 & 299 \\
\hline Poland & 4.4 & 14.9 & 7.6 & 750 \\
\hline Republic of Moldova & 0.3 & 38.0 & 58.9 & 621 \\
\hline Romania & 4.4 & 1.7 & 73.9 & 180 \\
\hline Russian Federation & 0.3 & 28.5 & 14.0 & 39207 \\
\hline Serbia & 43.8 & 7.9 & 24.7 & 89 \\
\hline Slovakia & 48.1 & 3.7 & 33.3 & 27 \\
\hline Slovenia & 73.5 & 2.9 & 11.8 & 34 \\
\hline $\begin{array}{l}\text { The former Yugoslav Republic } \\
\text { of Macedonia }\end{array}$ & 17.6 & 5.9 & 76.5 & 17 \\
\hline Tajikistan & 0 & 48.5 & 25.5 & 204 \\
\hline Turkey & 8.6 & 2.1 & 56.2 & 290 \\
\hline Ukraine & 0.3 & 53.8 & 42.6 & 13256 \\
\hline Uzbekistan & 0 & 65.9 & 22.4 & 2205 \\
\hline
\end{tabular}

\footnotetext{
*Data are presented according to three key transmission groups that are available from the EuroHIV report for the year 2006. As the number of cases attributable to mother-to-child transmission is small, these data are not presented. The proportion of unknown cases of transmission is not available from the EuroHIV report.

In Estonia, data on the mode of transmission are not available since 2002. Turkmenistan reported only two cases of HIV since 1989.

Data source: HIV/AIDS surveillance in Europe. End-year report 2006. Report No 75. Saint-Maurice: European Centre for the Epidemiological Monitoring of HIV/AIDS. Institut de Veille Sanitaire, 2007.
}

\section{RESULTS}

The country reports were received from all countries contacted except Azerbaijan and Lithuania.

\section{Estimates of the frequency of male same-sex behaviour}

Data on the prevalence of male same-sex sexual activity were available only in a few countries. They were assessed in surveys using different indicators, which limits the comparability. One per cent of men in Slovenia ${ }^{12}$ (age group 18-49) reported ever having homosexual intercourse while $4 \%$ of men in the survey in Latvia reported this (age group 15-49).${ }^{13}$ In Serbia, $2.4 \%$ of men aged 15-49 reported having sexual intercourse with another man in the past 12 months. ${ }^{14}$

\section{HIV case reporting}

From the start of reporting to EuroHIV, until the end of 2006, 3101 newly diagnosed HIV infections in MSM were reported in central Europe and 1828 in eastern Europe, out of 18253 and 343047 infections diagnosed among men, respectively. This is compared with 84561 cases among MSM in the 23 countries of Western Europe, out of 179135 HIV infections diagnosed among men. ${ }^{5}$

Table 1 shows the proportional contribution of key HIV transmission groups in the total number of newly diagnosed HIV cases reported in 2006 by EuroHIV. ${ }^{5}$ A high proportion of cases of homosexual transmission were found in the countries of central Europe, particularly in Slovenia, the Czech Republic, Croatia, Slovakia, Hungary and Serbia. A low proportion of cases attributable to homosexual transmission was reported in eastern Europe.

\section{HIV and STI prevalence}

The most recent data on HIV and STI prevalence among MSM are shown in table 2 and presented according to the robustness of the surveillance methods, starting with respondent-driven sampling (RDS) and time-location sampling (TLS) to convenience sampling. No HIV and STI prevalence data among MSM are available in Bosnia and Herzegovina, Cyprus, the Czech Republic, Hungary, the former Yugoslav Republic of Macedonia, Romania, Serbia, Tajikistan or Turkmenistan. As shown in table 2, results of HIV prevalence studies vary considerably. In the cities of four countries with data from RDS surveys, HIV prevalence is close to or higher than 5\% (Croatia, ${ }^{15}$ Estonia, ${ }^{16}$ Georgia $^{17}$ and Ukraine ${ }^{18}$ ). No cases of HIV were detected in surveys only using convenience sampling in Belarus, ${ }^{19}$ Bulgaria $^{20}$ and Kazakhstan ${ }^{21}$ and the Russian city Tomsk. ${ }^{22}$ The highest levels of HIV were found in convenience sample surveys in Tashkent, Uzbekistan $(10.8 \%)^{23}$ and in Odessa, Ukraine $(23.2 \%){ }^{18}$

Several countries such as Bulgaria, ${ }^{20}$ Croatia, ${ }^{15}$ Georgia, ${ }^{17}$ Kyrgyzstan, ${ }^{24}$ the Russian Federation (Yekaterinburg) ${ }^{22}$ and Turkey $^{25}$ have high lifetime syphilis prevalence among MSM (table 2). Prevalence data on herpes simplex virus type 2 (HSV- 
Table 2 The most recent data on HIV and STI prevalence among men who have sex with men, CCEE

\begin{tabular}{|c|c|c|c|c|c|c|}
\hline \multirow[b]{2}{*}{ Country, city and year of survey } & \multirow[b]{2}{*}{ Reference } & \multirow[b]{2}{*}{ Survey method; sample size } & \multicolumn{4}{|c|}{ Prevalence of infections $(\%)$} \\
\hline & & & HIV & Syphilis & Hepatitis B & Hepatitis C \\
\hline Albania, Tirana, 2005 & 30 & RDS; 200 & 0.8 & 1.2 & 17.6 & \\
\hline Estonia, Tallin and Harju, 2007 & 16 & RDS; 59 & 5 & 0 & 0 & \\
\hline Georgia, Tbilisi, 2005 & 17 & RDS; 70 & 4.2 & 27.1 & & \\
\hline Russian Federation & 31 & RDS, 267 & 0.8 & & & \\
\hline Ukraine, several sites, 2007 & 18 & & & & & \\
\hline Kiev & & RDS; 90 & 4.4 & & & \\
\hline Kryviy Rig & & RDS; 100 & 8.0 & & & \\
\hline Mykolayiv & & RDS; 100 & 10.0 & & & \\
\hline Odessa & & RDS; 69 & 23.2 & & & \\
\hline Russian Federation Moscow, 2005 & 27 & TLS; 303 & 0.9 & 0 & 1.9 & \\
\hline Kazakhstan, several sites, 2007 & 21 & Convenience; 450 & 0 & 3.1 & & 1.8 \\
\hline Kyrgyzstan, Bishkek, 2006 & 24 & Convenience; 100 & 1 & 23 & & 1 \\
\hline Latvia, Riga, 1998 & 33 & Convenience; 242 & 5.4 & & & \\
\hline Moldova, Chisinau, 2007 & 26 & Convenience; 94 & 4.8 & 6.5 & & 3.6 \\
\hline Poland, several sites, 2004 & 34 & Convenience; 404 & 4.7 & & & \\
\hline \multicolumn{7}{|l|}{ Russian Federation } \\
\hline Tomsk, 2003 & 22 & Convenience; 144 & 0 & 1.8 & & \\
\hline Yekaterinburg, 2003 & 22 & Convenience; 124 & 4.8 & 15.3 & & \\
\hline Nizhniy Novgorod, 2006 & 31 & Convenience; 108 & 9.3 & & & \\
\hline \multirow[t]{2}{*}{ Slovakia, Bratislava, 1996} & 35 & Convenience; 170 & 5.4 & & & \\
\hline & & Convenience; 124 & 1.6 & & & \\
\hline Slovenia, Ljubljana, 2006 & 36 & Convenience; 136 & 2.1 & & & \\
\hline
\end{tabular}

Empty cells indicate unavailability of data.

CCEE, countries of central and eastern Europe; RDS, respondent-driven sampling; STI, sexually transmitted infections; TLS, time-location sampling.

2) among MSM are only available from a study in Croatia, indicating a prevalence of $9.4 \% .{ }^{15}$ Data on gonococcal infection among MSM were found in only two countries: Croatia, rectal gonorrhoea, $13.2 \%{ }^{15}(\mathrm{n}=360)$ and Turkey, 3.0\% $(\mathrm{n}=166) .{ }^{25}$ Prevalence of rectal Chlamydia trachomatis infection was measured only in Croatia, and was found to be $9.0 \%$ $(n=360) \cdot{ }^{15}$ Data on the prevalence of antibodies to hepatitis B surface antigen (table 2 ) suggest that a vast majority of MSM are susceptible to hepatitis $\mathrm{B}$. The prevalence of hepatitis $\mathrm{C}$ infection in MSM in several countries (Croatia, ${ }^{15}$ the Republic of Moldova, ${ }^{26}$ the Russian Federation ${ }^{27}$ and Uzbekistan ${ }^{23}$ ) was higher compared to results among non-injecting MSM in studies carried out in the United Kingdom $(0.9 \%)^{28}$ and the United States $(1.5 \%),{ }^{29}$ which suggests transmission other than sexual.

More than one wave of HIV surveillance surveys is available in six countries, though small sample sizes and short time intervals limit the comparisons of data over time. HIV prevalence among MSM has increased in Yerevan, Armenia, from no cases found in a survey in $2002(n=50)$ to $2 \%$ in 2007 $(\mathrm{n}=100) .{ }^{32}$ In Minsk, Belarus, none tested positive in 2005 $(\mathrm{n}=170)$ and $2007(\mathrm{n}=279)$, while HIV prevalence in 2006 was $0.2 \%(\mathrm{n}=372) .{ }^{19}$ In Latvia, a survey carried out in Riga in 1997 found a prevalence of HIV of $2 \%(n=207)$, while in the survey carried out in 1998 in Riga and Liepaja HIV prevalence was 5.4\% $(\mathrm{n}=242) \cdot{ }^{33}$ In the Republic of Moldova, the first HIV survey among MSM conducted in $2003(n=120)$ found HIV prevalence of $1.7 \% .^{26}$ In the subsequent surveys in 2004 $(\mathrm{n}=120)$, HIV prevalence was $2.5 \%$, while in $2007(\mathrm{n}=94)$ it further increased to $4.8 \%{ }^{26}$ In surveys carried out in Kazakhstan in $2006(n=215)$ and in $2007(n=450)$, no cases of HIV were found. ${ }^{21}$ HIV prevalence monitoring among MSM in Slovenia has been carried out annually since 1996 by small-scale one-day surveys using convenience sampling. The sample size ranged from 82 to 136, with prevalence rates at $2.4 \%$ in $1996,3.7 \%$ in 2005 and $2.1 \%$ in $2006 .{ }^{36}$

\section{HIV-related behaviours}

Table 3 shows some behavioural indicators and data on selfreported testing on HIV from the most recent surveys, and the time frames used to assess these indicators.

No behavioural data are available in Bosnia and Herzegovina, Cyprus, Latvia, Romania, Tajikistan and Turkmenistan. Surveys that assessed only behaviours and not HIV or STI prevalence were carried out in the Czech Republic (2003), ${ }^{37}$ Hungary (2001), ${ }^{38}$ Serbia (2006) ${ }^{39}$ and the former Yugoslav Republic of Macedonia (2005). ${ }^{40}$

Use of condoms at last anal intercourse ranges from $36.0 \%$ in Turkey $^{25}$ to $87.7 \%$ in Moscow ${ }^{27}$ (table 3). Recent commercial sexual contacts were frequently reported in Belarus, ${ }^{19}$ Hungary, ${ }^{38}$ the Republic of Moldova, ${ }^{26}$ the Russian Federation ${ }^{31}$ and Ukraine ${ }^{18}$ (table 3 ). Reporting of ever-injecting drugs was the highest in Albania (27.1\%), ${ }^{30}$ the Republic of Moldova $(16.0 \%)^{26}$ and Nizhniy Novgorod $(11.1 \%)^{31}$ in the 
Table 3 The most recent HIV-related behavioural data among men who have sex with men, CCEE

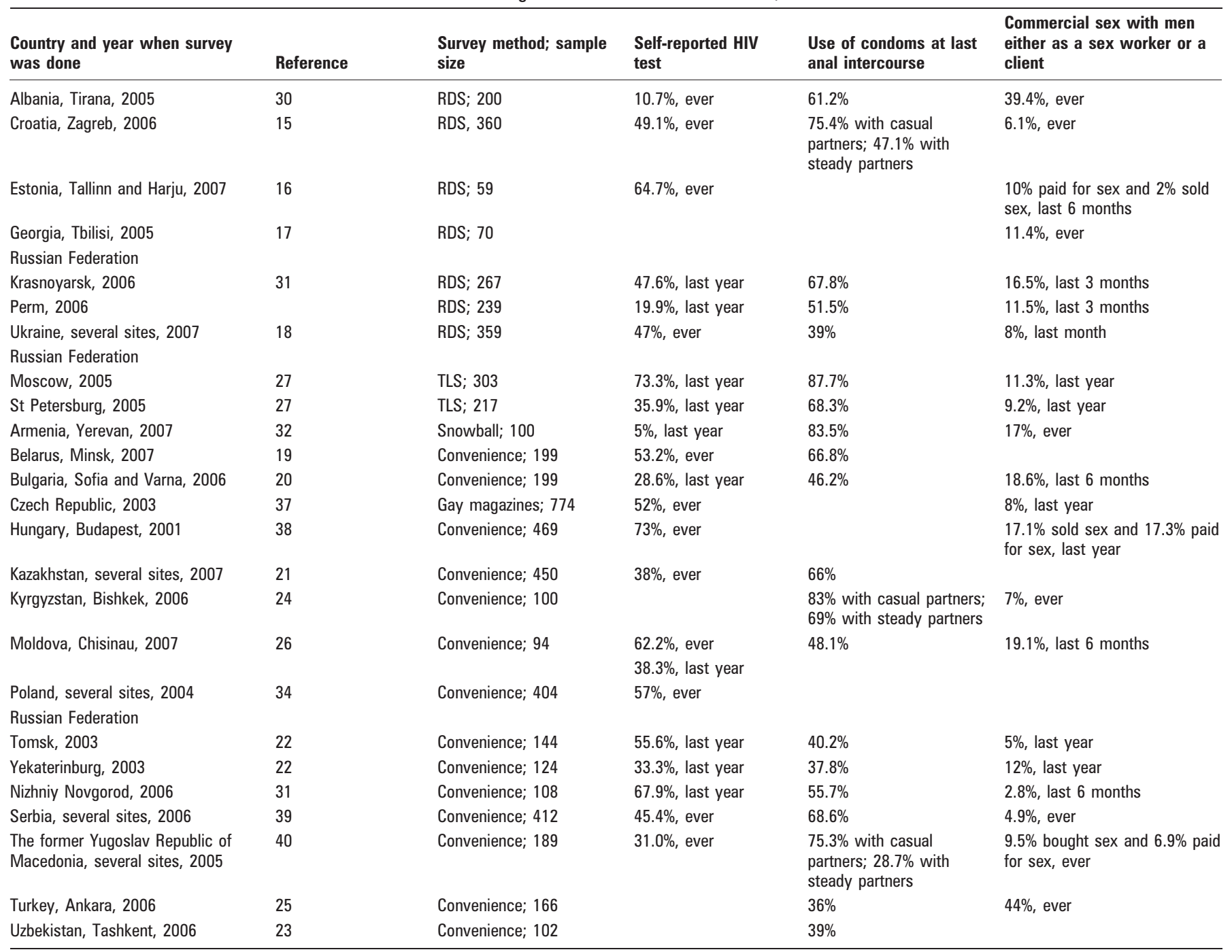

Empty cells indicate unavailability of data.

CCEE, countries of central and eastern Europe; RDS, respondent-driven sampling; TLS, time-location sampling.

Russian Federation. Current partnerships with women were frequently reported in surveys throughout the region, particularly in Albania (93.1\% in the last six months), ${ }^{30}$ Armenia (30\% in the last year), ${ }^{32}$ Bulgaria (45.7\% in the last six months), ${ }^{20}$ Czech Republic (17\% in the last six months), ${ }^{37}$ Hungary $(26.0 \%$ in the last year), ${ }^{38}$ the Russian Federation (ranging from $17.2 \%$ in the last year in Moscow to $44.8 \%$ in the last year in Krasnoyarsk), ${ }^{27}{ }^{31}$ Turkey (35.5\% in the last year), ${ }^{25}$ Ukraine $(22 \% \text { in the last year })^{18}$ and Uzbekistan $(38 \%$ in the last six months). ${ }^{23}$

\section{HIV prevention interventions among MSM in eastern Europe}

As described in the country reports, most HIV prevention services are currently provided by community-based organisations that have a small number of staff and lack capacities and funds to implement programmes more frequently and on a larger scale. More comprehensive prevention responses started at the beginning of the 2000s, particularly in the 16 countries that received funding from the GFATM. HIV-related prevention services among MSM consist of condom distribution, outreach work, internet-based counselling, face-to-face counselling and the distribution of educational materials. Country collaborators often mentioned the lack of staff, inadequate financial resources and unsupportive legal environments as important barriers to work. STI services are reportedly available in a few countries, though it is unclear the kind of tests and specimens that are used to make a diagnosis. Self-reported testing on HIV (table 3) is low, although in the last couple of years there has been an increase in voluntary counselling and testing (VCT).

The data on the coverage with prevention activities and the impact of prevention on HIV transmission were difficult to find. To describe the estimated coverage of MSM with prevention services we therefore used the most recent proposals for the GFATM grants because of the presumed comparability of such proposals and the lack of other data sources (table 4). ${ }^{41-56}$ In countries that are not eligible for GFATM funding, data on the coverage with HIV prevention interventions were not available. The coverage in the GFATM proposals is described either as an absolute number of MSM or a proportion of the estimated MSM population reached with prevention activities. In the majority of countries, HIV interventions include behavioural change communication and the provision of condoms, lubricants, educational materials and injecting equipment during outreach. The baseline coverage at the time of 
Table 4 Estimated coverage* with HIV prevention for men who have sex with men from the GFATM grant proposals, CCEE

\begin{tabular}{|c|c|c|c|c|}
\hline & Reference & $\begin{array}{l}\text { Baseline } \\
\text { year }\end{array}$ & $\begin{array}{l}\text { Baseline } \\
\text { coverage of } \\
\text { MSM (\% or } \mathrm{n} \text { ) }\end{array}$ & Measurement of the baseline coverage \\
\hline Albania & 41 & 2005 & 0 & No consistent prevention activities reported \\
\hline Armenia & 42 & NA & NA & NA \\
\hline Belarus & 43 & 2003 & $1 \%$ & $\begin{array}{l}\text { The coverage was estimated by the NGO Vstrecha and the } \\
\text { Republican Centre of Hygiene, Epidemiology and Public } \\
\text { Health from the HIV surveillance survey in which MSM } \\
\text { aged } 15-49 \text { were asked whether they were able to } \\
\text { access prevention services in the past } 12 \text { months }\end{array}$ \\
\hline $\begin{array}{l}\text { Bosnia and } \\
\text { Herzegovina }\end{array}$ & 44 & 2005 & $\mathrm{n}=483$ & $\begin{array}{l}\text { Data submitted to public health institutes on the number } \\
\text { of MSM who used services of NGOs }\end{array}$ \\
\hline Croatia & 45 & NA & NA & NA \\
\hline Kazakhstan & 46 & 2006 & $2.5 \%$ & $\begin{array}{l}\text { The coverage was estimated in rapid assessment surveys } \\
\text { carried out in Almaty, Shymkent, Aktobe, Karaganda and } \\
\text { Astana }\end{array}$ \\
\hline Kyrgyzstan & 47 & NA & NA & NA \\
\hline Moldova & 48 & NA & NA & NA \\
\hline Romania & 49 & 2005 & $10 \% ; n=2180$ & $\begin{array}{l}\text { Reports from the NGOs Accept and Population Services } \\
\text { International on the number of MSM reached with } \\
\text { prevention services }\end{array}$ \\
\hline $\begin{array}{l}\text { Russian } \\
\text { Federation }\end{array}$ & 50 & NA & NA & NA \\
\hline Serbia & 51 & 2006 & $n=5200$ & $\begin{array}{l}\text { Reports from NGOs SPY and Youth of Jazas submitted to } \\
\text { the Institute of Public Health on the number of MSM } \\
\text { reached with prevention services }\end{array}$ \\
\hline Tajikistan & 52 & NA & NA & NA \\
\hline $\begin{array}{l}\text { The former } \\
\text { Yugoslav Republic } \\
\text { of Macedonia }\end{array}$ & 53 & 2007 & $1.6 \%$ & $\begin{array}{l}\text { Reports from the NGO LGBT Centre submitted to the } \\
\text { Institute of Public Health on the number of MSM reached } \\
\text { with prevention services }\end{array}$ \\
\hline Turkey & 54 & 2002 & 0 & No prevention activites reported \\
\hline Ukraine & 55 & 2006 & $1.3 \%$ & $\begin{array}{l}\text { Data based on the reports of NGOs that provide prevention } \\
\text { services and assessed as part of the National Consensus } \\
\text { Estimates on HIV/AIDS in Ukraine in } 2006\end{array}$ \\
\hline Uzbekistan & 56 & 2002 & $<1 \% ; n=300$ & $\begin{array}{l}\text { Data submitted to the Republican AIDS Centre by NGOs } \\
\text { on the number of MSM reached with prevention services }\end{array}$ \\
\hline
\end{tabular}

${ }^{*}$ Coverage with HIV prevention is described either as an absolute number of MSM or a proportion of the estimated MSM population reached with prevention activities (mainly behavioural change communication and outreach services).

CCEE, countries of central and eastern Europe; GFATM, Global Fund to Fight AIDS, Tuberculosis and Malaria; MSM, men who have sex with men; NA, data are not available.

grants' submission was very low, averaging around $1-2 \%$, with the exception of Romania and Serbia, where it was slightly higher (table 4).

\section{Stigma and discrimination against MSM}

In a number of the countries reviewed, homosexual relationships were punishable by law until the mid-1990s, or even later, while in Turkmenistan and Uzbekistan homosexuality is still illegal and punishable by imprisonment. Available data from surveillance surveys or special studies show high levels of discrimination and violence towards gay people. Physical violence as a result of sexual orientation ranged from being reported by $10 \%$ of MSM in Georgia ${ }^{17}$ to $23 \%$ in Turkey. ${ }^{25}$ Psychological violence is more common, and ranges from $17 \%$ as reported by MSM in Hungary ${ }^{57}$ to $70 \%$ in Serbia. ${ }^{58}$ In some instances, the utilisation of healthcare and psychological services by MSM is hindered by a lack of healthcare professionals' knowledge of the sexual health needs of MSM. ${ }^{5960}$

\section{DISCUSSION}

Current evidence on the size of the HIV epidemic among MSM shows that HIV surveillance needs to focus on this group and embrace methods beyond case reporting. Continuing support from the GFATM and other donors for surveillance and prevention is essential, but has to be accompanied with destigmatisation (legal and societal) and changes in public health responses in order to meet the challenge of the evolving epidemics.

There is a substantial diversity between and within the CCEE with regard to the dynamics of HIV transmission among MSM. This is possibly due to differing times when HIV first occurred in the populations and the interplay of societal factors, injecting drug use, mobility and sex work.

Available data on the frequency of male-to-male sexual behaviour should be interpreted taking into account possible biases in reporting such behaviours. Low estimates of homosexual behaviour in Slovenia ${ }^{12}$ were explained by participation bias and men's fear of disclosing homosexual behaviour, while the country report in Latvia ${ }^{13}$ mentions that homosexuality is stigmatised and respondents might not have reported truthfully.

HIV case reporting is the mainstay of HIV surveillance in the CCEE. However, its coverage and completeness vary among the countries, depending on the existence and accessibility of VCT services, reporting practices and the extent to which MSM are willing to disclose the mode of transmission when diagnosed with HIV. Most of the prevalence surveys used convenience sampling, which limits the generalisability of these data. Few clinic-based prevalence data are available, including data from VCT centres and STI clinics. STI clinics that serve MSM population are rarely available in the CCEE, which explains the 
poorer availability of HIV and STI data from these sites, as well as rarely available prevalence estimates of STIs, such as gonorrhoea, Chlamydia trachomatis and HSV-2 from population-based surveys.

An important finding from this review is that there is a substantial discrepancy between the cumulative number of HIV cases reported among MSM in the national case reporting systems and the HIV prevalence reported in surveys, particularly in eastern Europe (Armenia, Georgia, the Russian Federation, Ukraine and Uzbekistan). For example, Ukraine has a reported prevalence in four cities in the range of $4.4 \%-$ $23.2 \%,{ }^{18}$ and the total number of MSM cases reported since 1987 is $110 .^{5}$ In the context of such under-reporting, populationbased HIV surveys have better public health utility in estimating the burden of HIV than the case reporting system, and can reach those parts of high-risk groups that have poor access to services. Public health benefit of surveillance would be maximised by having multiple data collection methods, in particular targeted population-based surveys and clinic-based sentinel surveillance. ${ }^{61}$

No studies were found that provided estimates of recent HIV infections. Nor were data found on serosorting and disclosure of HIV status. Male sex work remains unexplored in the region in spite of the high prevalence of commercial sexual contacts, particularly in the countries of eastern Europe. It is almost impossible to interpret STI epidemiology among MSM in the CCEE as there is a striking lack of data. Without knowing the extent of these problems, it is challenging to address them in the programmatic responses.

\section{Barriers to implementation of HIV prevention programmes}

The key barriers to implementation of prevention are the stigmatisation and discrimination of MSM and the subsequent difficult access to this community, coupled with weak surveillance on which effective prevention interventions should be based. The review of the GFATM proposals was undertaken because it was not possible to find well described activities of the programmatic responses and their results. The data on the estimated levels of coverage with HIV prevention from the most recent GFATM proposals, which are all written in the early and mid-2000s, were either low or not available. Underestimating the coverage for MSM and modest funding in many countries cannot make an impact on the HIV epidemic among MSM. Though stigma and discrimination are mentioned as the main obstacles to prevention among MSM, we were not able to find a comprehensive approach to addressing stigma and discrimination. Another key challenge to implementation of more comprehensive HIV prevention is the almost complete lack of evaluation of HIV prevention interventions in experimental studies in the CCEE. Only two randomised controlled trials evaluating the effect of HIV interventions done in the region were carried out, in the Russian Federation and Bulgaria. ${ }^{62}{ }^{63}$

The lack of MSM-specific STI screening services contributes to STIs being undiagnosed, particularly in the light of the high proportions of asymptomatic rectal infections. ${ }^{64}$ Along with the development of STI services for MSM, there is a need to scale up behavioural interventions and increase HIV testing and hepatitis $B$ vaccination uptake. ${ }^{65} 66$

\section{Needs for further research}

Further research should determine the size and characteristics of the MSM population, more robustly characterise the nature of the MSM HIV and STI epidemics and describe the nature of

\section{Key messages}

- The HIV epidemic among men who have sex with men (MSM) is well established in Croatia, Estonia, Latvia, Moldova, Poland, Ukraine, Uzbekistan and some cities in the Russian Federation.

- HIV-related behaviours among MSM are characterised by frequent commercial sex activities and partnerships with women.

- STI clinics that serve the MSM population are rarely available in the countries of central and eastern Europe, as are prevalence estimates of STIs.

- Key barriers to implementation of prevention are the stigmatisation of MSM, weak HIV surveillance systems, lack of evaluation studies and low funding for HIV prevention.

sexual networks of bisexual men and MSM who inject drugs, and assess their potential impact on population transmission of HIV. Research is also needed to describe the policy and legislative context within which these epidemics are occurring. Data on the extent and characteristics of discrimination and stigmatisation should be collected in special surveys or in surveillance surveys. Operational research is needed to explore the policy and programmatic issues that hinder or enable the implementation of HIV prevention services.

\section{Limitations of data sources}

Interpretation of survey data in the CCEE is limited by small sample sizes, short time-intervals of surveillance and the fact that population-based surveys have only recently started to be implemented. In the context of high stigmatisation of MSM, measurement, selection and participation bias and the social desirability bias - that is, when respondents reply in a manner that will be viewed favourably by others, have to be taken into account when interpreting findings. Ability to extrapolate the findings across the CCEE is limited because surveys are geographically limited to urban areas.

In conclusion, the HIV epidemic among MSM in the countries of central and eastern Europe, as in many other parts of the world, is hidden and prevention responses and surveillance are underfunded. The epidemic potential differs, underscoring the strategic importance of focusing prevention programmes on those areas where the potential for the expansion of the epidemic is more severe. This is particularly relevant for countries such as Croatia, Estonia, Latvia, the Republic of Moldova, Poland, Ukraine, Uzbekistan and some cities in the Russian Federation where the HIV epidemic among MSM is already well established. Programmatic efforts should improve HIV and STI surveillance and ensure that HIV prevention programmes are evidence-based and appropriately funded.

Acknowledgements: We are particularly grateful to the collaborators in 27 countries of eastern Europe who shared their resources. We are also grateful to those who conduct research on HIV among MSM in eastern Europe and programme implementers.

Funding: The original research that this paper is based on was funded by the World Health Organization Regional Office for Europe.

Competing interests: None.

Contributors: IB was the lead writer and did the literature search. LV and LZ collected data from the country collaborators and participated in the preparation of the manuscript. JVL and MM reviewed the drafts and made suggestions for their improvements. JVL also reviewed the references and drafted accompanying text where necessary. 


\section{REFERENTES}

1. Jaffe HW, Valdiserri RO, De Cock KM. The reemerging HIV/AIDS epidemic in men who have sex with men. JAMA 2007;298:2412-4.

2. Baral S, Sifakis F, Cleghorn F, et al. Elevated risk for HIV infection among men who have sex with men in low- and middle-income countries 2000-2006: a systematic review. Plos Med 2007; 4:e339.

3. UNAIDS and World Health Organization. AIDS epidemic update. Geneva, 2007.

4. UNAIDS and World Health Organization. Eastern Europe and Central Asia. AIDS epidemic update. Regional summary. Geneva, 2007.

5. Institut de Veille Sanitaire. HIVIAIDS surveillance in Europe. End-year report 2006. Report No 75. Saint-Maurice: European Centre for the Epidemiological Monitoring of HIV/AIDS, 2007.

6. Hamers FF, Devaux I, Alix J. HIV/AIDS in Europe: trends and EU-wide priorities. Euro Surveill 2006;11:E061123.1.

7. Dodds JP, Johnson AM, Parry JV, et al. A tale of three cities: persisting high HIV prevalence, risk behaviour and undiagnosed infection in community samples of men who have sex with men. Sex Transm Infect 2007;83:392-6.

8. Wright MT. Homosexuality and HIV/AIDS prevention: the challenge of transferring lessons learned from Western Europe to Central and Eastern European Countries. Health Promot Int 2005;20:91-8.

9. Rhodes T, Simic M. Transition and the HIV risk environment. BMJ 2004;331:220-3

10. Lyerla R, Gouws E, Garcia-Calleja JM. The quality of sero-surveillance in low- and middle-income countries: status and trends through 2007. Sex Transm Infect 2008;84(suppl 1):i85-i91.

11. Coker RJ, Atun RA, McKee M. Health care system frailties and public health control of communicable diseases on the European Union's new eastern borders. Lancet 2004;363:1389-92.

12. Klavs I. National survey of sexual lifestyles and Chlamydia trachomatis infection in Slovenia. [PhD dissertation] London: London School of Hygiene and Tropical Medicine, University of London, 2002.

13. Putnina A, Kelle I, Krastina Z. Reproductive health of the population: study on the situation in Latvia (1997-2003). Riga, 2003.

14. Ministry of Health of Republic of Serbia. Health survey in the population of Republic of Serbia. Belgrade, 2007

15. Bozicevic I, Djakovic Rode O, Lepej Zidovec S, et al. Prevalence of sexually transmitted infections among men who have sex with men in Zagreb, Croatia. AIDS Behav 2009;3:303-9.

16. Trummal A, Johnston LG, Lõhmus L. Men having sex with men in Tallinn: pilot study using respondent driven sampling. Tallinn: National Institute for Health Development, 2007.

17. Tatishvili M, Miminoshvili T. Characteristics, high-risk behaviors and knowledge of STI/HIVIAIDS and STI/HIV prevalence among men who have sex with men in Tbilisi, Georgia. Tbilisi: Association Tanadgoma, 2006

18. Balakiryeva ON, Bondar TV, Kasyanczuk MG, et al. Report on the survey "Monitoring behaviours of men having sex with men as a component of second generation surveillance". Kiev: International HIV/AIDS Alliance in Ukraine, 2008.

19. Meleshko LA, Ketchina EA, Zhdanovskaya OM, et al. Results of the sentinel surveillance for HIV-infection in the Republic of Belarus, report on surveys conducted in 2006. Minsk: Kovcheg LLC, 2007.

20. National Committee for Prevention of AIDS and STIs at the Council of Ministers of the Republic of Bulgaria. UNGASS progress report. Sofia, 2008.

21. Republican AIDS Center. Epidemiological situation in Kazakhstan: summary statistics. Almaty, 2008.

22. Smolskaya TT, Yakovleva AA, Kasumov VK, et al. HIV sentinel surveillance in highrisk groups in Azerbaijan, Republic of Moldova and in the Russian Federation. Copenhagen: World Health Organization, 2004

23. Ministry of Health. Strategic programme to combat the spread of HIVIAIDS in the Republic of Uzbekistan in 2007-2011. Tashkent, 2007.

24. National AIDS Center. Report on the sentinel epidemiological surveillance among MSM in the Kyrgyz Republic. Bishkek, 2006.

25. Institute for Public Health. Operations research on STIs and HIV in Turkey. Ankara: ICON, 2007.

26. National Centre of Health Management. National report: monitoring the Declaration of Commitment on HIVIAIDS. Chisinau, 2008.

27. WHO Regional Office for Europe. HIV prevalence and risks among men who have sex with men in Moscow and Saint Petersburg. Copenhagen, 2007.

28. Balogun MA, Ramsay ME, Parry JV, et al. A national survey of genitourinary medicine clinic attenders provides little evidence of sexual transmission of hepatitis $\mathrm{C}$ virus infection. Sex Transm Infect 2003;79:301-6.

29. Buffington J, Murray PJ, Schlanger K, et al. Low prevalence of hepatitis $C$ virus antibody in men who have sex with men who do not inject drugs. Public Health Reports 2007;122(suppl 2):63-7.

30. Bino S, Rjepaj K, Harxhi A, the Survey Working Group. Albania-behavioural and biological surveillance study report. Arlington: Family Health International, 2006.

31. Population Services International Research Division. HIVIAIDS study of forms of risky behaviour and the use of medical services by men having sex with men in two regions of the Russian Federation. Moscow, 2005.
32. National Center for AIDS Prevention. Behavioural and biological HIV surveillance in the Republic of Armenia 2007. Yerevan, 2007.

33. Ferdats A, Dievberna I, Upmace I, et al. Prevalence of HIV, hepatitis B and C and syphilis infections in different risk behaviour groups in Latvia. Geneva: 12th World AIDS Conference, 1998.

34. Izdebski Z. Research on men who have sex with men. Warsaw: TNS OBOP for National AIDS Centre, 2004.

35. Staneková D, Habeková M, Wimmerová S, et al. HIV infection and sexual behaviour among homosexual and bisexual men in Bratislava. Cent Eur J Public Health 2000;8:172-5.

36. Klavs I, Bergant N, Kustec T, et al. Infection with HIV in Slovenia: annual report 2006 Ljubljana: Slovenian Institute for Public Health, 2006.

37. Procházka I, Janík D, Hromada J. Social discrimination of lesbians, gay men and bisexuals in the Czech Republic. Prague: Gay Inciativa, 2003.

38. Csepe P, Amirkhanian YA, Kelly JA, et al. HIV risk behaviour among gay and bisexual men in Budapest, Hungary. Int J STD AIDS 2002;13:192-200.

39. Meskovic D. Behavioral surveillance survey on HIVIAIDS knowledge, attitudes, and practice among MSM. Belgrade: NGO Safe Pulse of Youth, 2006.

40. Republic Institute for Health Protection. Surveillance study and risk behaviours among most at risk populations. Skopje, 2007.

41. Global Fund to Fight AIDS, Tuberculosis and Malaria. Original Proposal, HIV/ AIDS, Albania, 5th Round. Geneva, 2005.

42. Global Fund to Fight AIDS, Tuberculosis and Malaria. Grant Scorecard, Armenia, 2nd Round. Geneva, 2005.

43. Global Fund to Fight AIDS, Tuberculosis and Malaria. Original Proposal, HIV/ AIDS, Belarus, 3rd Round. Geneva, 2003.

44. Global Fund to Fight AIDS, Tuberculosis and Malaria. Original Proposal HIV/ AIDS and Tuberculosis Components, Bosnia and Herzegovina, 5th Round. Geneva, 2005.

45. Ministry of Health and Social Welfare of the Republic of Croatia. Final Report on the Grant Agreement between the Global Fund to Fight AIDS, Tuberculosis and Malaria and Ministry of Health and Social Welfare of the Republic of Croatia. Zagreb, 2007.

46. Global Fund to Fight AIDS, Tuberculosis and Malaria. Original Proposal HIVI AIDS, Kazakhstan, 7th Round. Geneva, 2007.

47. Global Fund to Fight AIDS, Tuberculosis and Malaria. Original Proposal HIVI AIDS, Kyrgyzstan, 7th Round. Geneva, 2007.

48. Global Fund to Fight AIDS, Tuberculosis and Malaria. Original Proposal HIV/ AIDS, Moldova, 6th Round. Geneva, 2006.

49. Global Fund to Fight AIDS, Tuberculosis and Malaria. Original Proposal HIV/ AIDS, Romania, 6th Round. Geneva, 2006.

50. Global Fund to Fight AIDS, Tuberculosis and Malaria. Original Proposal HIV/ AIDS, Russia, 4th Round. Geneva, 2004.

51. Global Fund to Fight AIDS, Tuberculosis and Malaria. Original Proposal HIVI AIDS, Serbia, 6th Round. Geneva, 2006.

52. Global Fund to Fight AIDS, Tuberculosis and Malaria. Original Proposal HIV/ AIDS, Tajikistan, 6th Round. Geneva, 2006.

53. Global Fund to Fight AIDS, Tuberculosis and Malaria. Original Proposal HIV/ AIDS, Republic of Macedonia, 7th Round. Geneva, 2007.

54. Global Fund to Fight AIDS, Tuberculosis and Malaria. Original Proposal HIV/ AIDS, Turkey, 4th Round. Geneva, 2004.

55. Global Fund to Fight AIDS, Tuberculosis and Malaria. Original Proposal HIVI AIDS, Ukraine, 6th Round. Geneva, 2006.

56. Global Fund to Fight AIDS, Tuberculosis and Malaria. Original Proposal, HIV/ AIDS, Uzbekistan, 6th Round. Geneva, 2006.

57. Tóth L. Gay sexual lifestyles and social impact of homophobia in Hungary. Hungarian Venereological Archivum 1997;: I/2:95-105.

58. Research of violence among LGBT population in Serbia. Belgrade: Labris, 2006

59. Association for Free Sexual Orientation. Annual report. Skopje, 2007

60. Open Society. Access to health care for LGBT people in Kyrgyzstan. Bishkek, 2007.

61. Aral So. Determinants of STD epidemics: implications for phase appropriate intervention strategies. Sex Transm Infect 2002;78(suppl 1):i3-13.

62. Amirkhanian YA, Kabakchieva E, Kirsanova AV, et al. A randomized social network HIV prevention trial with young men who have sex with men in Russia and Bulgaria. AIDS 2005;19:1897-905.

63. Kelly JA, Amirkhanian YA, Kabakchieva E, et al. Prevention of HIV and sexually transmitted diseases in high risk social networks of young Roma (Gypsy) men in Bulgaria: randomised controlled trial. BMJ 2006;333:1089.

64. Kent CK, Chaw JK, Wong W, et al. Prevalence of rectal, urehtral and pharyngeal chlamydia and gonorrhoea detected in 2 clinical settings among men who have sex with men: San Francisco, California. Clin Infect Dis 2005;41:67-74.

65. Herbst JH, Sherba T, Crepaz N, et al. A meta-analytic review of HIV behavioural interventions for reducing sexual risk behaviour of men who have sex with men. J Acquir Immune Defic Syndr 2005;39:228-41.

66. Workowski KA, Levine WCL. Sexually transmitted disease treatment guidelines. MMWR 2002:51(RR06):1-80. 